\title{
Feasibility and utility of active case finding of HIV-infected children and adolescents by provider-initiated testing and counselling: evidence from the Laquintinie hospital in Douala, Cameroon
}

\author{
Calixte Ida Penda ${ }^{1,2^{*}}$, Carole Else Eboumbou Moukoko², Daniele Kedy Koum', Joseph Fokam ${ }^{3,4}$,
} Cedric Anatole Zambo Meyong ${ }^{2}$, Sandrine Talla ${ }^{5}$ and Paul Koki Ndombo ${ }^{4,6}$

\begin{abstract}
Background: Universal HIV testing and treatment of infected children remain challenging in resource-limited settings (RLS), leading to undiagnosed children/adolescents and limited access to pediatric antiretroviral therapy (ART). Our objective was to evaluate the feasibility of active cases finding of HIV-infected children/adolescents by provider-initiated testing and counseling in a health facility.

Methods: A cross-sectional prospective study was conducted from January through April 2016 at 6 entry-points (inpatient, outpatient, neonatology, immunization/family planning, tuberculosis, day-care units) at the Laquintinie Hospital of Douala (LHD), Cameroon. At each entry-point, following counseling with consenting parents, children/adolescents (0-19 years old) with unknown HIV status were tested using the Rapid Diagnostic Test (RDT) (Determine ${ }^{\oplus}$ ) and confirmed with a second RDT (Oraquick ${ }^{\oplus}$ ) according to national guidelines. For children less than 18 months, PCR was performed to confirm every positive RDT. Community health workers linked infected participants by accompanying them from the entry-point to the treatment centre for an immediate ART initiation following the «test and treat » strategy. Statistical analysis was performed, with $p<0.05$ considered significant.

Results: Out of 3439 children seen at entry-points, 2107 had an unknown HIV status (61.3\%) and HIV testing acceptance rate was $99.9 \%$ (2104). Their mean age was $2.1(\mathrm{Sd}=2.96)$ years, with a sex ratio boy/girl of 6/5. HIV prevalence was $2.1 \%$ (44), without a significant difference between boys and girls $(p=0.081)$. High rates of HIV-infection were found among siblings/descendants (22.2\%), TB treatment unit attendees (11.4\%) and hospitalized children/ adolescents (5.6\%); $p<0.001$. Up to $95.4 \%$ (42/44) of those infected children/adolescents were initiated on ART. Overall, 487 (23.2\%) deaths were registered (122 per month) and among them, 7 (15.9\%) were HIV-positive; mainly due to tuberculosis and malnutrition.
\end{abstract}

Conclusion: The consistent rate of unknown HIV status among children/adolescents attending health facilities, the high acceptability rates of HIV testing and linkage to ART, underscore the feasibility and utility of an active case finding model, using multiple entry-points at the health facility, in achieving the 90-90-90 targets for paediatric HIV/AIDS in RLS.

Keywords: HIV testing, Children, Adolescents, Entry points, MTCT, Cameroon

\footnotetext{
* Correspondence: idapenda@yahoo.fr

${ }^{1}$ Clinical sciences department, Faculty of Medicine and Pharmaceutical

Sciences, University of Douala, PO Box 2071, Douala, Cameroon

${ }^{2}$ HIV Care and Treatment Centre, Laquintinie Hospital of Douala, Douala,

Cameroon

Full list of author information is available at the end of the article
}

(c) The Author(s). 2018 Open Access This article is distributed under the terms of the Creative Commons Attribution 4.0 International License (http://creativecommons.org/licenses/by/4.0/), which permits unrestricted use, distribution, and reproduction in any medium, provided you give appropriate credit to the original author(s) and the source, provide a link to the Creative Commons license, and indicate if changes were made. The Creative Commons Public Domain Dedication waiver (http://creativecommons.org/publicdomain/zero/1.0/) applies to the data made available in this article, unless otherwise stated. 


\section{Background}

Paediatric HIV/AIDS remains a public health priority in children and adolescents worldwide, with 150,000 new infections occurring among children in 2015 [1], with over seventy-nine thousand $(79,771)$ children and adolescents aged 0-19 years were living with HIV and almost half of them were 10 years and older during the same year $[1,2]$. Most HIV-infected children are diagnosed late, at an advanced stage of disease progression $[2,3]$. This programmatic challenge is of great concern because without antiretroviral therapy (ART), 53\% of HIV-positive children die before their second birthday [4]. Thus, challenges in ensuring universal paediatric HIV testing and linkage to care are the driving force in reducing the gap between paediatric coverage and antiretroviral therapy (ART). Out the 1.8 million children living with HIV under the age of 15, only half are on ART worldwide, $20 \%$ of them in West and Central Africa in 2015 [5, 6]. Of note, at the time when paediatric ARVs were introduced in Cameroon in 2003, the number of HIV-infected children under 15 years was estimated at 50,334 and 50,284 for those in need of treatment. Though free access to ART (effective since 2007), coupled to progress in the WHO recommendations, has doubled the number of HIV-positive children accessing ART in Cameroon (3114 in 2007 to 6099 [11\%] in 2014), the number children in need of ART (51,910 in 2014) remains very high, in the frame of a persistent paediatric HIV incidence nationwide (i.e. 4100 new infections reported in 2015) [7].

Several initiatives to scale up paediatric care have been implemented in recent years: i) the global Elimination Plan of MTCT in 2011 ii) the "Double Dividend" Initiative in 2013 through joint efforts of UNICEF, EGPAF and WHO with the dual goal of ending paediatric HIV epidemic and improving child survival in high HIV prevalence settings; and iii) "Accelerate Children's HIV/AIDS Treatment Initiative" by PEPFAR and UNAIDS [8]. Cameroon has endorsed the UNAIDS strategic 90-90-90 targets: 90\% of HIV-infected children and adolescents know their status, 90\% of HIV-infected children who know their status are receiving ART and 90\% of ART-experienced children have viral suppression [9]. Timely achievement of these targets requires implementing the "Test early, Test closer and Treat earlier" approach for every child and adolescent at all entry points of health facilities [8-10]. Successful implementation of this approach in linking to care warrants an assessment of HIV testing and access to ARVs for children/adolescents living with HIV and to improve quality of supply and demand for services. Our study objective was to ascertain the effectiveness of an active HIV case-finding model in HIV testing and linkages to care of children/adolescents at different entry points of a health facility in a RLS like Cameroon.

\section{Methods}

\section{Study design}

A cross-sectional and prospective study was conducted at the level of all 6 entry points of children and adolescents' units of the Laquintinie hospital of Douala (LHD) in the Littoral region of Cameroon from January through April 2016. LHD has an Approved Treatment Centre (ATC) for HIV/AIDS day care where in 91\% attendees are adults versus $9 \%$ children and adolescents. LHD is a centre of excellence for pediatric HIV care, with an active cohort of 452 children and adolescents that represents up to $32 \%$ HIV-infected children receiving ART in the Littoral region of Cameroon.

\section{Description of the study site}

The HLD has 6 entry points of for pediatric care: (i) Pediatric inpatient unit that includes: Pediatric emergency, general pediatric hospitalizations, nutrition and sickle cell disease unit; (ii) Neonatology unit including premature babies and PMTCT services; (iii) Pediatric outpatient unit; iv) immunization and family planning unit; (v) Tuberculosis Screening and Management Unit (TB unit); and (vi) the day-care hospital/Approved treatment centre (ATC) for people living with HIV (PLWHIV): Adult unit and pediatric unit of care and treatment of PLWHIV. Regarding PMTCT, all of exposed HIV infant in our facility were managed in the PMTCT program. Nevirapine was administered for 6 weeks irrespective of the mode of feeding selected by the mother if she took ART (preferentially TDF $+3 \mathrm{TC}+\mathrm{EFV}$ ) for more than 1 month and for 12 weeks if the mother did not take ART or took them for less than one month.

\section{Sampling method}

All children and adolescents aged 0-19 years, of unknown HIV status, or descendants of PLWHIV or siblings of HIV infected children, were consecutively by convenient sampling enrolled during the 4 months study period (January-April 2016). In the absence of real data on the prevalence of paediatric HIV infection for active HIV case finding in Cameroon, a minimum size for the study was calculated using the HIV prevalence of $15.4 \%$ based on a systematic review conducted on children and adolescents in sub-Saharan Africa [10], with $\mathrm{z}$ at $95 \%$ IC (i.e. $\mathrm{z}=1.96$ ) and an error rate of 0.05 ; to determine the minimum sample size using Cochran's formula $\left(\mathrm{z}^{2 *} \mathrm{p} * \mathrm{q} / \mathrm{d}^{2}\right)$ [11], given a minimum of 201 children/adolescents for the study.

\section{Model of identification process and the patient flow}

We developed a service model to actively look for cases of HIV-infected children and adolescents at all entry points at the LHD (Fig. 1). For every child and adolescent seeking care at any entry point of the LHD, we asked parents or guardians if the child's HIV status was 


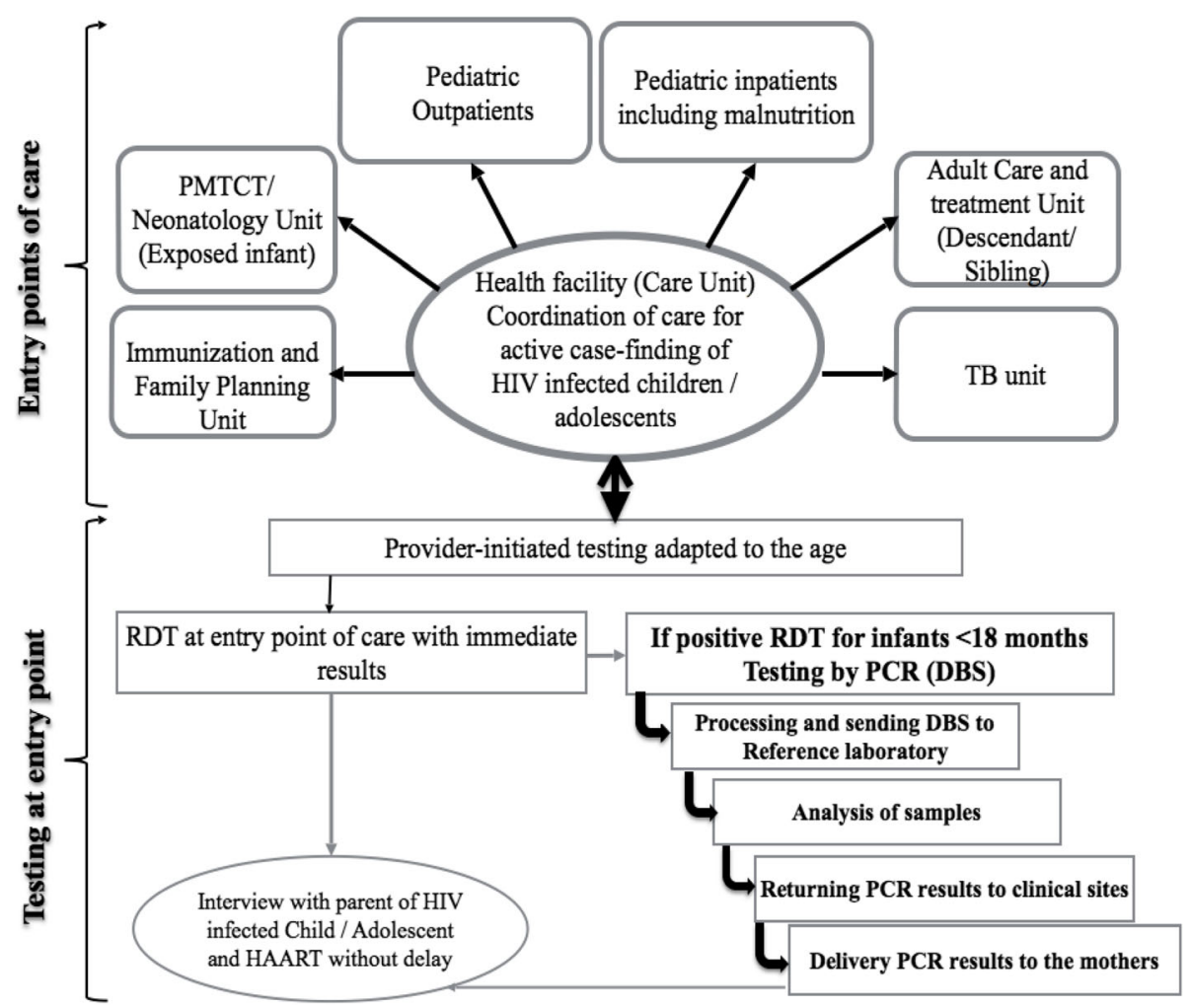

Fig. 1 Identification model and screening of HIV for a child/adolescent at entry point of care in the central hospital level. DBS: dried blood spots; HAART: highly active antiretroviral therapy; HIV: human immunodeficiency virus; PCR: polymerase chain reaction; PMTCT: prevention of mother to child transmission of HIV; TB: tuberculosis; RDT: rapid diagnostic test

known and documented. If the answer was "no", or "I don't know", information on the need for HIV testing was provided to parents by a trained community health worker (CHW) who provided pre-test counselling, written informed consent, onsite HIV testing and result delivery immediately after the post-test counselling. Additionally, all adult PLWHIV attending the ATC of the LHD were asked to take their descendant(s) aged 0-19 years whose HIV status was not known; for HIV-infected children attending the ATC, an active case finding of their siblings was also done. For descendants and siblings, study information was provided to parents during clinic attendance at the level of the waiting room, in order to enhance their motivation in bringing their family members for HIV testing. Then, a family tree of the descendants and siblings was developed from the index patient to determine the number of children and adolescents with unknown HIV status. The parent/guardian then decided on the location for HIV testing of the child or adolescent, who could be either at health facility or home-based. Additionally, HIV status of the mother was sought before carrying out the test of the neonate, infant and child.

The study pre-testing phase consisted of an administration of study tools (closed questions with single or multiple answers) to 20 parents/guardians over a period of one week in order to: (i) assess their understanding and acceptability and (ii) standardize and homogenize the data collection tools at the level of all entry points of the healthcare facility (Fig. 1).

\section{Procedure for HIV screening}

Based on a serial algorithm as per the national guidelines for HIV testing (Fig. 2), a rapid diagnostic test (RDT) was offered to consenting parents of participating children, with immediate result delivery, by task shifting from laboratory technicians to trained healthcare providers. Briefly, the first RDT (Determine ${ }^{\text {Tx }}$ HIV-1/2) was performed using capillary blood from the child/adolescent as per the manufacturer's instructions, with a sensitivity of $100 \%(98.5-100)$ and a specificity of $95.8 \%$ (93.3-98.4) for HIV-1/2 evaluated locally [12]. After $15 \mathrm{~min}$, the result was provided and post-test counselling done accordingly. In case of a non-reactive HIV result, the child/adolescent has declared HIV-negative (i.e. free of HIV-infection); in case of a reactive HIV result, a second more specific RDT (Oraquick') was performed as per the manufacturer's instructions, with a sensitivity of 96.7\% (94.4-98.9) and a specificity of $100 \%(98.5-100)$ to confirm HIV 


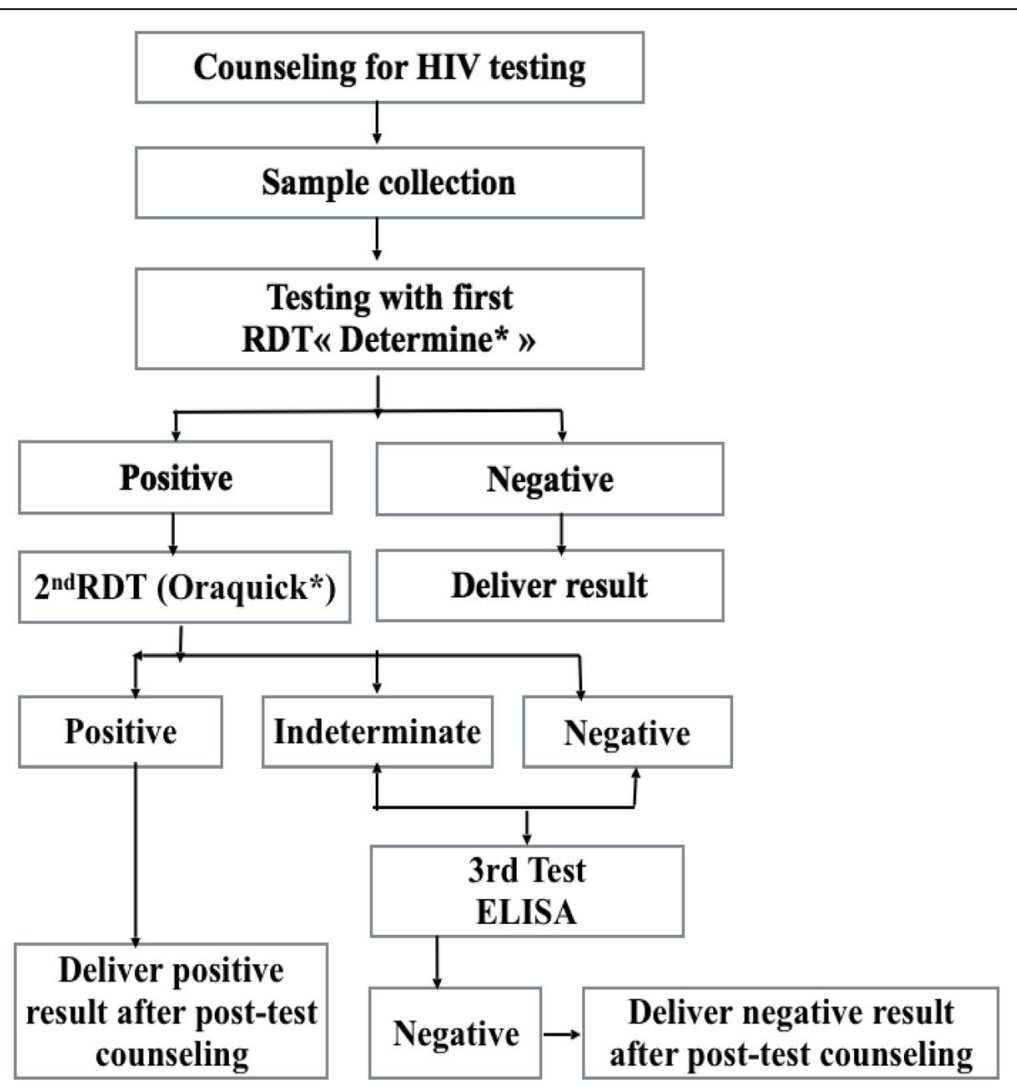

Fig. 2 Screening Algorithm of HIV infection. ELISA: enzyme linked immunosorbent assay; HIV: human immunodeficiency virus; RDT: rapid diagnostic test

infection, as per local assessment [12]. In case of discordant results between the two RDTs, an ELISA test (ELISA" Genscreen $^{\text {TM }}$ ULTRA HIV Ag - Ab) was performed as tier breaker following the manufacturer's instructions (i.e to confirm or exclude HIV-infection). Post-test counselling was provided prior to result delivery. In case of a reactive HIV result after RDT in an infant $<18$ months, a blood sample was collected from a prick on the heel, toe or finger, directly into a filter paper (Whatman $n^{\circ}$ 903) for a confirmation of the result by polymerase chain reaction (PCR). Of note, the HIV status of the mothers was sought before carrying out the test of the neonate, infant or child. For HIV-vertically exposed infants of less than 18 months, the serological test reflects the exposure to HIV through their mothers, which requires testing by PCR to either confirm or infirm HIV-infection. For any HIV-positive child/adolescent, CHWs accompanied the concerned from the entry point to the ATC for an immediate initiation on ART according to the strategy of «test and treat». The parents /legal guardians were provided with therapeutic education by a psychosocial agent. Children tested HIV-positive at inpatient services were also initiated on ART and monitored throughout their hospitalization (Fig. 2).

\section{Statistical analyses}

Categorical variables were expressed as frequency, while the quantitative variables were presented as means \pm Standard deviations (SD) or with 95\% interval confidence (IC 95\%) if normally distributed. To compare proportions, we used Fisher exact test. Quantitative values were compared using the U-test of Wilcoxon test. Only variables with a $p$-value $\leq 0.2$ in the univariate model were considered for analysis in a multivariate logistic regression model. All statistical analyses were performed using the Stata (version 11SE) and R (version 3.1.1 software). $P$-value $<0.05$ was considered statistically significant.

\section{Results}

Basic characteristics and acceptability of HIV testing among study participants

Overall, 3439 interviews were conducted to parents/legal guardians of children/adolescents attending the LHD, and up to 2107 children/adolescents were reported to have an unknown HIV status, indicating a rate of $61.3 \%$ unknown HIV infection in this paediatric population (Fig. 3).

Three parental refusals of consent were recorded, among which one each from the in-patient unit, outpatient unit and family tree model, giving 99.9\% (2104/2107) 


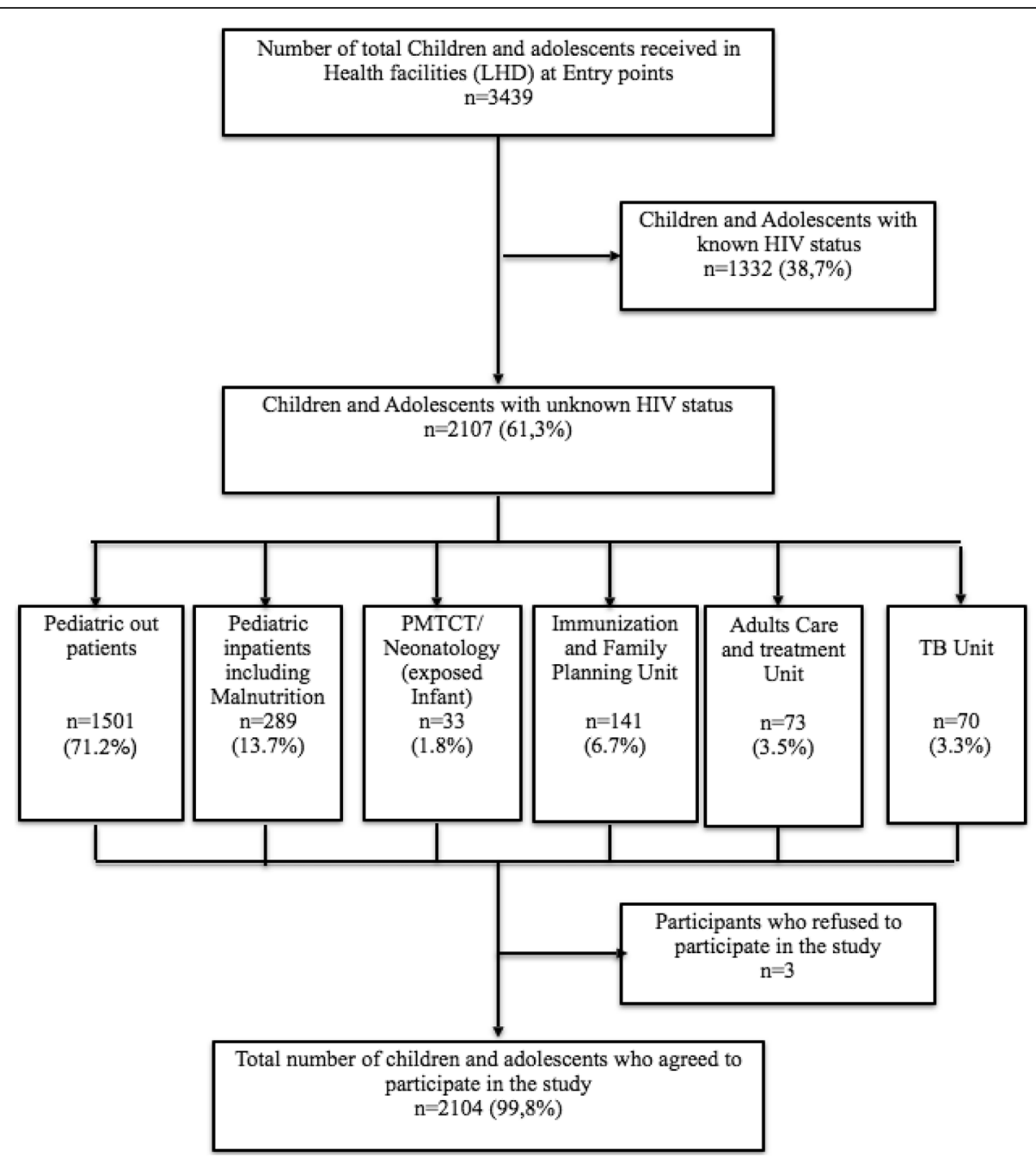

Fig. 3 Flow diagram of child/adolescent enrolled in the Study. HLD: Laquintinie hospital of Douala; HIV: human immunodeficiency virus; PMTCT: prevention of mother to child transmission of HIV; TB: tuberculosis

acceptability rate for enrolment and HIV testing in the entire study population (Fig. 3).

Among 2104 children and adolescents enrolled, the majority came from outpatient unit (71.29\%), followed by hospitalized patients (13.69\%), as shown in Table 1 . Immunization and family planning unit contributed $6.69 \%$ of children and adolescents. A comparison of acceptability based on the six entry-points showed no significant difference in performance $(p=0.090)$.

Overall, among 2104 children and adolescents included boys accounted for $54.71 \%$ and the boy/girl sex ratio was $6: 5(1151 / 953)$ and the mean age of $2.10(\mathrm{Sd}=2.96)$ years. The age class 3-6 years of boys was significantly higher compared to that of girls $(15.0 \%$ vs. $11.2 \%$ for girl, $p=0.015$ ) (Table 1). No difference was observed between the number of girl and boys patients according to entry point of care. However, the mean age was significantly higher among children enrolled from the family tree model $(5.47+/-\mathrm{Sd}=4,33)$ and from the tuberculosis (TB) unit $(4.81+/ \mathrm{Sd}=4,50$ years $)$, as compared to that of children/adolescents enrolled from in-patient services, $(p=0.0001)$.

\section{HIV prevalence and linkage to ART care according to entry points}

Out of 2104 children and adolescents tested for HIV, 44 were diagnosed as HIV-positive, giving an overall prevalence of $2.1 \%$ (Table 2). According to entry points, the highest rates of HIV-infection were reported among siblings/descendants, TB unit attendees and hospitalized patients, respectively with 22.2, 11.4 and 5.6\%, with statistically significant differences among participants from siblings/descendants, outpatient unit, immunization and family planning $(p \leq 0.001)$. Of note, none $(0 \%)$ of the 141 infants enrolled from the immunization unit was positive, 
Table 1 Basic characteristics of the study population by sex and age range

\begin{tabular}{|c|c|c|c|c|}
\hline Variables & Girls & Boys & Total & $P$ \\
\hline Number of participants enrolled: $n$ (\%) & $953(45.3)$ & $1.151(54.7)$ & $2.104(100.0)$ & \\
\hline \multicolumn{5}{|l|}{ Entry point of care } \\
\hline Pediatric Inpatients Unit ${ }^{*}$ & $116(12.2)$ & $172(14.9)$ & 288 & 1 \\
\hline Pediatric out patient Unit & $679(71.2)$ & $821(71.3)$ & 1.500 & 0.121 \\
\hline TB Unit & $37(3.9)$ & $33(2.8)$ & 70 & 0.056 \\
\hline Vaccination and Family Planning Unit & $71(7.4)$ & $70(6.1)$ & 141 & 0.048 \\
\hline PMTCT/Neonatology Unit & $21(2.2)$ & $12(1.0)$ & 33 & 0.010 \\
\hline Adult care and treatment Unit (Descendant/Sibling) & $29(3.0)$ & $43(3.7)$ & 72 & 0.898 \\
\hline Mean Age $(\mathrm{Sd})$, years & $2.06(2.95)$ & $2.13(2.96)$ & $2.10(2.96)$ & 0.329 \\
\hline$[0-3]^{a}$ & $756(79.3)$ & $875(76.0)$ & $1.633(77.5)$ & 1 \\
\hline [3-6] & 95 (10.0) & $154(13.4)$ & $249(11.8)$ & 0.015 \\
\hline [6-9] & $49(5.1)$ & $67(5.8)$ & $116(6.5)$ & 0.391 \\
\hline [9-11] & $22(2.3)$ & $18(1.6)$ & $40(1.9)$ & 0.354 \\
\hline [11-15] & $25(2.6)$ & $31(2.7)$ & $56(2.7)$ & 0.801 \\
\hline [15-19] & $6(0.6)$ & $6(0.5)$ & $12(0.6)$ & 0.801 \\
\hline
\end{tabular}

Data are number and/or proportion (\%), unless otherwise indicated; PMTCT prevention of mother to child transmission of HIV, SD standard deviation, $T B$ tuberculosis; ${ }^{\mathrm{a}}$ : Reference

and only $2(0.1 \%)$ of the 1500 children enrolled from outpatient unit were HIV-positive.

Among the 44 HIV positive children and adolescents, $42(95.5 \%)$ were successfully accompanied by CHWs to the ATC and were all enrolled into care according to the national guidelines for pediatric management of HIV/AIDS. Thus, this gives a very high linkage to care among HIV-positive children/adolescents, with only $4.5 \%$ refusal. Prior to ART initiation, two died during hospitalization for malnutrition and TB. Among the $40 \mathrm{HIV}$-infected children/adolescents who effectively initiated on ART, 5 died subsequently, giving an overall mortality rate of $15.9 \%$ (7/44) of HIV positive children/adolescents enrolled in the study (Table 3). In contrast, within the population of HIV-negative children, up to $23.2 \%$ (480) mortality rate was reported mainly due to life threatening paediatric emergencies (Table 3). This gives an overall mortality rate of $23.2 \%$ (487), resulting to 122 deaths per month.

\section{Discussions}

In order to contribute to the global efforts for ending AIDS, we designed and implemented a strategy for universal HIV testing and enrolment to care of all infected children/adolescents in RLS. Our model of multiple entry points to healthcare was highly accepted by parents/legal guardians (>99\%), similar to findings from Uganda (92.8\%) and Kenya (82.5\%) [11, 13, 14]. These indicate a high success rate of such approach in RLS, which contributes in achieving the 90\% HIV diagnosis among children/adolescents with unknown status [9]. In this frame, Provider Initiated Testing and Counselling (PITC) for the children are feasible.

Table 2 Distribution of population according to HIV status at different entry points of care

\begin{tabular}{|c|c|c|c|c|}
\hline \multirow[t]{2}{*}{ Entry point of care } & \multicolumn{4}{|c|}{ HIV status, n (\%) } \\
\hline & $\begin{array}{l}\text { HIV Negative } \\
2060 \text { (97.9) }\end{array}$ & $\begin{array}{l}\text { HIV Positive } \\
44 \text { (2.09) }\end{array}$ & $\begin{array}{l}\text { Total } \\
2104\end{array}$ & $P$ \\
\hline Pediatric inpatients Unit ${ }^{a}$ & $272(94.4)$ & $16(5.56)$ & 288 & 1 \\
\hline Out Pediatric patient Unit & $1498(99.9)$ & $2(0.1)$ & 1500 & $<0.0001$ \\
\hline TB Unit & $62(88.6)$ & $8(11.4)$ & 70 & 0.078 \\
\hline Immunization and Family Planning Unit & $141(100.0)$ & 0 & 141 & 0.004 \\
\hline PMTCT/Neonatology unit & $31(93.9)$ & $2(6.1)$ & 33 & 0.905 \\
\hline $\begin{array}{l}\text { Adult care and treatment Unit } \\
\text { (Descendant/Sibling) }\end{array}$ & $56(77.6)$ & $16(22.2)$ & 72 & $<0.0001$ \\
\hline
\end{tabular}

Data are number and/or proportion (\%), unless otherwise indicated; ${ }^{a}$ : Reference; TB Tuberculosis, PMTCT Prevention of mother to child transmission of HIV 
Table 3 Mortality in the population of HIV-infected and uninfected children /adolescents

\begin{tabular}{|c|c|c|c|c|c|c|c|}
\hline \multirow{3}{*}{$\begin{array}{l}\text { Survival } \\
\text { status }\end{array}$} & \multicolumn{7}{|c|}{ Patients } \\
\hline & \multicolumn{2}{|c|}{ HIV Infected } & \multicolumn{2}{|c|}{ HIV Uninfected } & \multicolumn{2}{|l|}{ Total } & \multirow[b]{2}{*}{$P$} \\
\hline & $n$ & $\%$ & $n$ & $\%$ & $n$ & $\%$ & \\
\hline Died & 7 & 15.9 & 480 & 23.2 & 487 & 23.2 & 1 \\
\hline Alive & 37 & 84.1 & 1580 & 76.8 & 1617 & 76.8 & 0.85 \\
\hline
\end{tabular}

HIV human immunodeficiency virus, $n$ number; \%: proportion

Our model of active linkage to care, using CHWs for liaison persons, showed an excellent enrolment into care of HIV-positive children/adolescents $(>95 \%)$. Thus, the current model, if well implemented, would contribute in achieving 90\% of ART coverage in HIV-infected children/adolescents [9].

Routinely, HIV testing is offered to suspect children or those under the PMTCT program, both accounting for only $10 \%$ of children attending consultation and those admitted to the hospital. Of note, the prevalence was low in PMTCT/Neonatology due to maternal exposure to ART, except for children of HIV-infected mother who missed the PMTCT program and were discovered at delivery or postnatal unit (Neonatology). Moreover, task shifting of HIV testing to non-health professionals $(\mathrm{CHW})$, under guardian/parental counselling, significantly reduces waiting time and increases access/acceptability to testing [15].

The mean age of our study population was 2.1 years, higher than those in Bamenda-Cameroon (1.3 year) and in Zambia (1 year) $[16,17]$. Nonetheless, these observations altogether indicate late HIV diagnosis in RLS, with high mortality among infected children if untreated [15]. In this model, there is need for ensuring earlier diagnosis and treatment in order to limit HIV-associated mortality $[18,19]$. This is crucial for siblings/descendants with unknown HIV status, who often have very late diagnosis (5.47 years in our finding). As previously reported, using family tree as a key to identify unreported children living with HIV and increase paediatric ART would be relevant $[10,15,20,21]$.

HIV prevalence from our study was lower $(\sim 2 \%)$ than those from Malawi and Uganda but higher than that of Kenya $[13,15,16,19]$; disparities being mainly attributed to varying epidemics in these different geographical settings. HIV prevalence varies by entry point, with a high burden at the ТВ Unit (11.4\%), similar to findings from Ethiopia (14.5\%) [22]. TB unit should be considered as a secondary point to catch-up missing cases of paediatric HIV for linkage to care in RLS [22, 23], thus closing the gap in paediatric ART coverage $(\sim 40$ increased fold in Uganda) [24].

The rate of HIV-associated mortality (15.9\%) was similar to those in West and Central Africa (16\%) in 2014 [25].
However, the high mortality (23.2\%) among HIV-negative children was due to late hospital attendance with life threatening emergencies in the frame of malnutrition, TB and encephalopathy. Of note, as a referral centre, the LHD as a referral centre receives cases with clinical complications from primary healthcare facilities and with higher risk of mortality, thereby justifying the surprisingly high mortality rates among HIV-negative children.

A major strength of our findings is the high sensitivity of Determine (100\%) used as first RDT and the high specificity of Oraquick (100\%) used as second RDT, as reported by Njouom et al. in Cameroon [12], indicating accuracy in identifying the real serological status. However, studies on costing of the current model, that integrates community-based HIV-testing, linkage to care and viral load coverage in pediatric populations, would provide further evidences for policy-making toward ending paediatric AIDS in RLS [1, 9].

\section{Conclusion}

A model of HIV testing of children/adolescents at multiple entry points and active linkage to care is feasible and efficient in achieving universal paediatric ART coverage in African RLS. With emphasis on family tree, TB, and/or hospitalised children/adolescents, this model would greatly contribute in achieving the current global targets for paediatric HIV in Cameroon and in other RLS.

\section{Abbreviations \\ AIDS: Acquired immunodeficiency syndrome; ART: Antiretroviral therapy; ATC: Approved Treatment Centre; CHW: Community health workers; EGPAF: Elizabeth Glaser Pediatric AIDS Foundation; HIV: Human immunodeficiency Virus; LHD: Laquitinie Hospital of Douala; PCR: Polymerase Chain Reaction; PEPFAR: US President Emergency Fund for AIDS Relief; PLWHIV: People Living with HIV; PMTCT: Prevention of Mother-to-Child Trans- mission; RDT: Rapid Diagnostic Test; RLS: Resource-Limited Settings; TB: Tuberculosis; UNAIDS: Joint United Nations Programme on HIV/AIDS; UNICEF: United Nations Children's Fund; WHO: World health organization}

\begin{abstract}
Acknowledgements
We are very grateful to the questionnaire respondents who agreed to participate in this study. We express our gratitude to the LHD wards, EGPAF and Landry Dongmo Tsague Senior HIV/AIDS Specialist/UNICEF Western and Central Africa Regional Office for their support and cooperation during the survey. Statistical analysis and data interpretation were supported by the International Society for Health Research and Training (ISRT-Health), a local Lecturer network.
\end{abstract}

\section{Funding}

The present study was supported by the University of Douala and the Laquintinie Hospital of Douala.

\section{Availability of data and materials}

The datasets supporting the conclusions of this article are included within the article and its related tables and figures.

\section{Authors' contributions}

CIP, CEEM, DKK, PKN, CAZM and ST designed the study and collected the data. CIP, JF and CEEM analysed and interpreted the data. CIP and JF initiated the manuscript. CEEM, DKK, PKN, CAZM, and ST revised the manuscript. All authors read and approved the final version of the manuscript. 


\section{Ethics approval and consent to participate}

This study was conducted in accordance with ethics regulations for research on humans in Cameroon. The Institutional Review Board of the University of Douala (IRB/UD) approved the study. Administrative authorization was obtained from the LHD. Before enrolment and the administration of questionnaire, parents or legal guardians were informed on the purpose and process of the investigation (background, goals, methodology, study constraints, respect of privacy and data confidentiality, and rights to opt out from the study), and a signed informed assent was obtained from all parents or legal guardians for inclusion and use of anonymous data of their children in publication and conference presentations. Participation was voluntary, anonymous and without compensation.

\section{Consent for publication}

Not applicable.

\section{Competing interests}

The authors declare that they have no competing interests.

\section{Publisher's Note}

Springer Nature remains neutral with regard to jurisdictional claims in published maps and institutional affiliations.

\section{Author details}

'Clinical sciences department, Faculty of Medicine and Pharmaceutical Sciences, University of Douala, PO Box 2071, Douala, Cameroon. ${ }^{2}$ HIV Care and Treatment Centre, Laquintinie Hospital of Douala, Douala, Cameroon ${ }^{3}$ Virology Laboratory, Chantal Biya International Reference Centre for research on HIV/AIDS prevention and management, Yaoundé, Cameroon. ${ }^{4}$ Faculty of Medicine and Biomedical Sciences, University of Yaoundé I, Yaoundé, Cameroon. ${ }^{5}$ Technical office, Elizabeth Glaser Pediatric AIDS Foundation, LDH, Douala, Cameroon. ' ${ }^{6}$ Mother-Child Centre, Chantal BIYA Foundation, Yaoundé, Cameroon.

Received: 31 January 2018 Accepted: 24 July 2018

Published online: 03 August 2018

\section{References}

1. Joint United Nations Programme on HIV/AIDS. UNAIDS. On the Fast-track to an AIDS-Free generation.The incredible journey of the global plan towards the elimination of new HIV infections among children by keeping theirs mothers alive; 2015. https://www.unaids.org/sites/default/files/media_asset/ GlobalPlan2016_en.pdf.Geneva. Accessed 18 July 2016.

2. Comité National de lutte contre le SIDA, UNAIDS. Rapport 2015. Estimations et projections sur le VIH et le SIDA au Cameroun. Période: 2010-2020; 2015. http:// cnls.cm/sites/default/files/estimation_et_projections_sur_le_vih_et_le_sida_au_ cameroun_2010-2020_rapport_2015.pdf. Accessed 18 July 2016.

3. Joint United Nations Programme on HIV/AIDS.UNAIDS. 2015 Progress report on the global plan towards the elimination of new HIV infections among children and keeping their mothers alive; 2015. http://www.unaids.org/sites/ default/files/media_asset/JC2774_2015ProgressReport_GlobalPlan_en.pdf.

4. Newell ML, Coovadia H, Cortina-Borja M, Rollins N, Gaillard P, Dabis F. Ghent International AIDS Society (IAS) Working Group on HIV Infection in Women and Children. Mortality of Infected and Uninfected Infants Born to HIV-Infected Mothers in Africa: A pooled analysis. Lancet. 2004;364(9441):1236-43.

5. UNAIDS/UNICEF/WHO Global AIDS Response Progress Reporting and UNAIDS 2016 estimates; 2016. https://www.unicef.org/publications/index_93427.html. Accessed 18 July 2016

6. United Nations Children's Fund. For every child, end AIDS - seventh stocktaking report. New York: UNICEF; 2016. Accessed 25 July 2017

7. UNAIDS. AIDSinfo. National database. Cameroon. http://www.unaids.org/fr/ regionscountries/countries/cameroon. Accessed 25 July 2017.

8. WHO. Global health sector response to HIV, 2000-2015: focus on innovations in Africa: progress report. Geneva; 2016. Accessed 25 July 2017.

9. UNAIDS. Understanding Fast-Track: accelerating action to end the AIDS epidemic by 2030. Geneva; 2015. https://jifilc.com/resources/understandingfast-track-accelerating-action-to-end-the-aids-epidemic-by-2030/. Accessed 14 Jun 2016.

10. Govindasamy D, Ferrand RA, Wilmore SM, Ford N, Ahmed S, Afnan-Holmes $\mathrm{H}$, Kranzer K. Uptake and yield of HIV testing and counselling among children andadolescents in sub-Saharan Africa: a systematic review. J Int AIDS Soc. 2015;18:20182.
11. Cochran WG. Sampling techniques. 3rd ed. New York (NY): John Wiley and Sons; 1977. Available at https://archive.org/stream/Cochran1977Sampling Techniques_201703/Cochran_1977_Sampling\%20Techniques_djvu.txt

12. Njouom R, Ngono L, Mekinda-Gometi DD, Kengne CN, Sadeuh-Mba SA, Marie-Astrid Vernet MA, Tchendjou P, Vernet G. Evaluation of the performances of twelve rapid diagnostic tests for diagnosis of HIV infection in Yaounde, Cameroon. J Virol Meth. 2017;243:158-63.

13. Wanyenze RK, Nawavvu C, Ouma J, Namale A, Colebunders R, Kamya MR. Provider-initiated HIV testing for paediatric inpatients and their caretakers is feasible and acceptable. Tropical Med Int Health. 2010;15(1):113-9. https:// doi.org/10.1111/j.1365-3156.2009.02417.x.

14. Muhula S, Memiah P, Mbau L, Oruko H, Baker B, Ikiara G, et al. Uptake and linkage into care over one year of providing HIV testing and counselling through community and health facility testing modalities in urban informal settlement of Kibera, Nairobi Kenya. BMC Public Health. 2016;16(1):373-9.

15. McCollum ED, Preidis GA, Kabue MM, Singogo EBM, Mwansambo C, Kazembe PN, et al. Task shifting routine inpatient pediatric HIV testing improves program outcomes in urban Malawi: a retrospective observational study. PLoS One. 2010;5(3):e9626.

16. Zoufaly A, Hammerl R, Sunjoh F, Jochum J, Nassimi N, Awasom C, et al. High HIV prevalence among children presenting for general consultation in rural Cameroon. Int J STD AIDS. 2014;25(10):742-4.

17. Kankasa C, Carter RJ, Briggs N, Bulterys M, Chama E, Cooper ER, et al. Routine offering of HIV testing to hospitalized pediatric patients at university teaching hospital, Lusaka, Zambia: acceptability and feasibility. JAIDS J Acquir Immune Defic Syndr. 2009;51(2):202-8.

18. Violari A, Cotton MF, Gibb DM, Babiker AG, Steyn J, Madhi SA, Jean-Philippe $P, M c I n t y r e ~ J A, C H E R$ study team. Early antiretroviral therapy and mortality among HIV-infected infants. N Engl J Med. 2008;359(21):2233-44.

19. Wachira J, Ndege S, Koech J, Vreeman RC, Ayuo P, Braitstein P. HIV testing uptake and prevalence among adolescents and adults in a large homebased HIV testing program in Western Kenya. J Acquir Immune Defic Syndr. 2014;65(2):e58-66

20. Lewis Kulzer J, Penner JA, Marima R, Oyaro P, Oyanga AO, Shade SB, et al. Family model of HIV care and treatment: a retrospective study in Kenya. J Int AIDS Soc. 2012;15(1):8-13.

21. Ramirez-Avila L, Noubary F, Pansegrouw D, Sithole S, Giddy J, Losina E, et al. The acceptability and feasibility of routine pediatric HIV testing in an outpatient Clinic in Durban, South Africa. Pediatr Infect Dis J. 2013;32(12):1348-53.

22. Westerlund E, Jerene D, Mulissa Z, Hallström I, Lindtjørn B. Pre-ART retention in care and prevalence of tuberculosis among HIV-infected children at a district hospital in southern Ethiopia. BMC Pediatr. 2014;14:250.

23. UNAIDS. Joint United Nations Programme on HIV/AIDS. Cameroon developing subnational estimates of HIV prevalence and the number of people living with HIV. 2014 Geneva. [http://www.unaids.org/en/resources/ documents/2014/2014_subnationalestimatessurvey_cameroon. Accessed 14 June 2016.

24. Luyirika E, Towle MS, Achan J, Muhangi J, Senyimba C, Lule F, et al. Scaling up Paediatric HIV care with an integrated, family-Centred approach: an observational case study from Uganda. PLoS One. 2013;8(8):69548.

25. Dicko F, Desmonde S, Koumakpai S, Dior-Mbodj H, Kouéta F, Baeta N, et al. Reasons for hospitalization in HIV-infected children in West Africa. J Int AIDS Soc. 2014;17:1881.

Ready to submit your research? Choose BMC and benefit from:

- fast, convenient online submission

- thorough peer review by experienced researchers in your field

- rapid publication on acceptance

- support for research data, including large and complex data types

- gold Open Access which fosters wider collaboration and increased citations

- maximum visibility for your research: over $100 \mathrm{M}$ website views per year

At BMC, research is always in progress.

Learn more biomedcentral.com/submissions 